sunken; voice peculiarly shrill (vox cholerica). The last few stools had not been thrown away, and on examination I found them to present the appearance of rice gruel, with feculent white matter of an albumenous nature floating in it. Had only vomited once, and that at half-past nine ; I saw him at ten and gained the above information from bis wife's sister. The spasms in the thighs and legs were then most violent. His hands and arms and feet cold as ice, and of a blackish livid purple colour; countenance as described; body universally cold; pulse extremely low, sometimes scarcely to be felt at the wrist, about 80 in the minute. Had passed no urine that the bystanders knew of in the night. My mind was quite made up that he would die. I therefore prepared his relatives to expect such an event, as I had seen several other cases with precisely the same symptoms, which were no more severe than those in this case. Gave him a table-spoonful of flour of mustard, and a table-spoonful of table salt in half a pint of warm water, followed by half a pint more warm water; tied up his arm, and when the emetic began to operate, opened a vein from which $I$ obtained twelve ounces of very black and thick blood, which when coagulated showed but little serum. Applied a mustard poultice down the spine, from the nucha to the sacrum; gave him after the emetic had operated and the bleeding was over:-

Hydrarg. submuriatis, gr. $\mathrm{v}$;

Opii, gr. iij ;

Hydr. submus', gr. ij, et

Opii, gr. ss; 2a quaq. horá, cum ß̧iss mistura seq.;

Bo Piper. cayencis,, $\mathrm{j}$.

Aq. Ballient. Oss. infundi per horam et cola, tunc adde liquoris ammonice

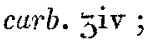

(ahout gr.viij carb. ammon. for a dose), with a tablespoonful of brandy in 3 ss of very hot water in the intermediate hour, and a quarter of a pint of hot beef-tea every hour. Covered him with hot blankets; applied hot sand-bags to the extremities; arms and leos to be rubbed with hot flannel in a clirection to the heart; injected into the bowels three pints of hot water with ziss of brandy. Puroing ceased, and spasms gone, after the bleeding and first dose of calomel and opium. In three hours extremities a little warmer; pulse a little more distinct; lividity much less; countenance more natural ; voice still peculiar. Injected water came away; repeated the hot water and brandy injection. Continue the mixture, La quaq. hor $\hat{u}$ et pill. 4 a quaq. horâ. Mustard poultice to remain on; renew the hot sand.

Seven p.M. Bowels not open since the bleeding; no spasms since; extremities warm; lividity quite gone; countenance natural; voice natural. No urine passed; pulse much stronger, and regular. $\mathrm{He}$ ap. pears now in the state of a patient in collapse in typhus fever. Congestion appears about the head. Calomel and opium every six hours; the mixture of capsicum every three hours. Continue the brandy and hot water; the hot-water injection renew.

10th, ten A.m. Symptoms all better, much rallied; yet still great disposition to sleep, and appearance of congestion in the head; applied six large leeches to the forehead. Omit the calomel and opium; repeat the mixture every four, five, or six hours.

Ten P.M. Congestion about the head much relieved; animated; had passed no urine until to-night for 43 hours.

11th. Convalescent; no subsequent fever; urine natural ; had passed a loose stool, which appeared to be beef-tea.

12th. Had passed threo loose feculent stools. Recovering, yet weak.

13th. Gums tender from the calomel.

ON THE

\section{SULPHATE OF INDIGO}

AS A

TEST FOR NITRIC ACID.

To the Editor of The LANCET.

Srr,-Were I not conscious of the truth of what I am about to advance, I would not on any account encroach upon your valuable pages; but as you have always shown a wish to publish whatever might benefit the public in general, and medical practitioners in particular, I hope you will allow me a column of your journal for the publication of what $I$ consider entitled to some attention, which I will endeavour to make as concise as possible.

I have lately gone over the interesting experiments of Dr. O'Shaughnessy on nitric acid, and I am glad to find that this acid, from being one of the most difficult to test in cases of medical jurisprudence, bas become, comparatively speaking, one of the easiest. But in two or three instances I am compelled to differ from him. The first is in the formation of the detonating cyanate of silver: he observes, that white flakes begin to fall within the space of three $\mathrm{mi}$ nutes after the mixture has attained to the boiling point. Now out of more than thirty experiments, repeated exactly as is laid down in the text, I never once succeeded in less than a quarter of an hour. Generally I was above half an hour, and five or 
six times not at all. I will not say that had duped chemists for so long a time, by this is an exaggeration on the part of Dr. blotting from his valuable pages that test, 0 'Shaughnessy, but we must all allow, the utter fallacy of which had been so inthat in the hands of a youthful experiment- disputably established. It appears to me, alist it might never succeed, or otherwise however, that Dr. Turner knew too well the he might not have patience to persevere. strength of the evidence on which he Add to this, the mixture must contain more grounded his assertion, to concede what the pure nitric acid than is specified, for instance, three drops. Such being the case, the test itself, I presume, is hardly deserving the commendations the above toxicologist has been pleased to pass upon it, as from my own observations it cannot be employed when the acid is moderately diluted.

The next point to which I have an objection, is in the formation of nitrate of urea. This, he says, may be formed by adding the smallest drop of nitric acid to urine, evapornted down to the consistence of syrup. Such is precisely the case; but on coning to the conclusion of the passage, he observes that oxalic acid has the same effect. Now, Mir. Editor, do not suppose I am ignorant of the abilities of the man whose paper I am now criticising; I have perused his publications too attentively, and followed him through all the intricacies of his experiments too closely, to doubt for a moment his profound skill, whether in the laboratory or elsewhere, but for all this I will not yield to him one iota of what 1 have alleged; $I$ am tjo well aware of its exactness to give up the point so readily. That oralic acid produces the same change, I deny; for out of as many experiments performed with that test as were made with the cyanate of silrer, I did not succeed once. Again; duluted nitric acid, in this instance, is of no utility whatever; therefore I should conceive that urine would be of little service in cases of poisoning, unless some portion of the undiluted acid by which the deceased was destroyed could be procured, which however I believe is not often the case.

I now come to the third and last point, which is in the instance of sulphate of indigo. Dr. O'Sbaughnessy has entered into a long argument on the inutility of this preparation as a test for nitric acid, and from the almost insuperable evidence which he has advanced in its support, it may appear presumptuous in me to doubt it; but encouraged by what you have observed in your introduction to the practical commentaries on Dr. Christisons Processes for Detecting Poisons, I have determined, though not without mature consideration, to come forward and say a word or two in support of the old established test. I was rather surprised, on reading your review of Dr. Turner's Chemistry, to find that you were in perfect concordance with $\mathrm{Dr}$. O'Shaughnessy, blaming the former gentleman for not correcting the error which generality of toxicologists knew to be a fact, to that which, comparatively speaking, had been no more than suggested. May 1 ask you, Mr. Editor, whether you have repeated the experiments in question, and whether you have come to the same conclusions as Dr. O'Shaughnessy, or you have, omitting that very useful method which you have followed with Dr. Christi. son, trusted to the profound knowledge and high reputation of your correspondent, and with your accustomed consciousness of truth, based what you were advancing on the words of another?

Excuse this deviation; I will now come directly to the point, and in order to expose the falsity of Dr. O'Shaughnessy's experiments, 1 will just beg leave to 'quote the paragraph on this head from Dr. Turner, and then contrast it with that of your correspondent.

Dr. Turner observes, that a new test of the presence of nitric acid has recently been proposed by Dr. Liebig : the liquid to be examined must be mixed with a sufficient quantity of a solution of the sulphate of indigo in sulphuric acid; for acquiring a distinct blue colour a few drops of sulphuric acid to be added, and the mix ture boiled. If a nitrate is present the liquid will be bleached, or if the quantity is very small, rendered yellow; by this process nitric acid may be detected, though diluted with 400 times its weight of wate $\mathbf{r}$; or by adding a little muriate of soda to the liquid before applying heat, one five-hundredth part of nitric acid may be discovered.

So much for Dr. Turner, now for Dr. O'Shaughnessy. He says, "A few test tubes were filled to the same height with water, and the fluid tinced to the same depth of shade by the blue solution of indigo in sulphuric acid. Dr. Liebig's process with the nitric acid was performed on the first, and the colour was immediately discharged as he describes. To the fluid in a second tube a few drops of sulphuric acid were added, as Dr. Turner desires in the process for nitric acis, and the colour, on the mixture reaching the boiling print, was discharged as effectually as in the first experiment. A third trial was made with muriatic acid alone in the same quantity, and the tint was again destroyed; and in a fourth experiment two grains of the muriate of soda, with one minim of the sulphuric acid, produced the same effect."

Ihese experiments I repeated almost 
times innumerable, and every trial gave|their appearance, when the colour is dis. additional proofs of the truth of what I had charged, would be enough to discover the before observed. I poured into each of nitric acid, could no other test be brought five test tubes about half a drachm of water to our assistance.

coloured lightly with the blue solution of In conclusion, MIr. Editor, I would just sulphate of indigo; this done, I let fall into ask you, wheiher, out of the numerrus the first one drop of nitric acid, into the trials 1 have griven this test upon the acids, second the same quantity of muriatic arid, I might not by chance have succeeded into the third as much sulphuric acid, into once. Can you suppose it possible, that, the fourth two grains of muriate of soda, however carelessly 1 tried these experiwith one minim of sulphuric acid, and into ments, I could miss stumbling on the right the fifth as much nitrate of potash and sul- way at least once, ard thus have establish. phuric acid as the mariate-of-soda solution ed the facts advancel by Dr. O'Shaugh contained. Then 1 applied each succes- nessy? But I never did once succeed, and sively to the flame of a spirit-lamp, and after boiling about half a minute, the colour of the nitric acid and nitrate of potash mixtures was entirely dispersed, leaving the liquid of a fine straw colour. That which contained the muriatic acid lost a little of its tint when heated, but quite sufficient remained to distinguish it from the nitric acid. This is shown to more advantage by bringing them to each other, and placing the tubes on a dirty napkin. The other two were not in the least affected. Often as I tried these experiments, the blue colour was always discharged by nitric acid on the mixture reaching the boiling point, and even without heat, providing enough acid had been added. I see no necessity for the drop of sulphuric acid being made use of, as proposed by Professor Liebig, as it has no perceptible effect upon the liquids, nor can I conceive how it should, when the indigo itself is dissolved in that menstruum, even concentrated. It contradicts the facts which, by the theory of Dr. O'Shanghnessy, it attempts to establish ; or why is not the blue colour lost in the formation of the sulphate of indigo itself? for there a very moderate heat is applied. Your correspondent has remarked that the solutions ongiht only to be coloured very lightly, or the change will not take place; but I wouli add, that such is not the case with nitric acid, for however dark or however light the colour, providing the acid bo in pro. portion, the shade is discharged; whereas the sulphuric and muriatic acid mixtures may be but tinted with the blue test, and the acids themselves added in large quantities, and yet, on being heated, little or no decolorisation takes place.

But granting what Dr. O'Shaughnessy alleges, would not the difference of efiect, in point of time, be sufficient to stamp the utility of the sulphate of indigo in this instance? In the meantime, we must not forget, that chlorine and muriate of tin possess the same properties of decolorising the indigo solution; but the effect which morphia has upon nitric acid will suffi. ciently distinguish the one in question from the other two; besides, the difference in each experiment was performed with every possible care, and exactly in the manner laid down by your " Correspondent." Much more might be offered in confirmation of what I have already said, but I fear even now I have trespassed too long upon your time, therefore, leaving you and your readers to give the above remarks the strictest scrutiny, I conclude by subscribing myself

Your constant Reader, JOHN S. HILIY.

Elland, near Halifax,

March 10, 1332.

LONDON PHRENOLOGICAL SOCIETY.

January 16,1832 .

Dr. Erliotson in the Chair.

\section{LIFE AND CHARACTER OF} DR. PARR.

TIIIs evening the following paper was read by Mr. SEDGwick on the phrenological development and character of Dr. PARR:-

At our last phrenological meeting, the Society's collection becanie enriched through the kindness of a member, Mir. Whitwell, by the cast of the head of the late cele. brated Dr. Parr. My name standing third on the list of those who bave entered into an engagement, each in his turn, either to write or provide a paper for the Society, the duty has this evening derolved upon me, and I embrace with pleasure the opportunity afforded me by Mr. Whitwell, to call your attention to some points in the history and character of that remarkable person, in connexion with his phrenological development-than which a more striking instance of the trutb of our science cannot I think be adduced. It is to be remembered that our principal object is the collection of facts, and in this it is advisable to select well-authenticated cases, such as the present, where the character of the individual is well known, but which would 